NOTICE: this is the author's version of a work that was accepted for publication in Composites Part B-Engineering. Changes resulting from the publishing process, such as peer review, editing, corrections, structural formatting, and other quality control mechanisms may not be reflected in this document. Changes may have been made to this work since it was submitted for publication. A definitive version was subsequently published in Composites Part B-Engineering, Vol.50, (2013). DOI: 10.1016/j.compositesb.2013.01.013 


\section{Elsevier Editorial System(tm) for Composites Part B Manuscript Draft}

Manuscript Number:

Title: Characterisation of cotton fibre-reinforced geopolymer composites

Article Type: Full Length Article

Keywords: A. Polymer-matrix composites, B. Microstructures, B. Mechanical properties, B. Fracture toughness.

Corresponding Author: Prof. It-Meng (Jim) Low, PhD

Corresponding Author's Institution: Curtin University

First Author: Thamer Alomayri, MSc

Order of Authors: Thamer Alomayri, MSc; Faiz A Shaikh, PhD; It-Meng (Jim) Low, PhD

Abstract: This paper describes the physical, mechanical and fracture behaviour of geopolymer reinforced with cotton fibres. Four different cotton fibre contents are considered as reinforcements for geopolymer composites based on fly-ash. Results show that the appropriate addition of cotton fibres can improve the mechanical properties of geopolymer composites. In particular, the flexural strength and the fracture toughness increase at an optimum fibre content of $0.5 \mathrm{wt} \%$. However, as the fibre content increases, the density of geopolymer composites decreases due to an increase in porosity.

Suggested Reviewers: htchak Tchakoute Kouamo PhD

Laboratoire de Physico-Chimie des Matériaux Minéraux, Université de Yaoundé

htchak@yahoo.fr

Expertise in fly-ash based geopolymer

Mihail Criado PhD

Centro Nacional de Investigaciones Metalúrgicas (CSIC)

mcriado@cenim.csic.es

Expert in geoplymer composites

Opposed Reviewers: 
Dear Editor

Please find attached a manuscript entitled "Characterisation of cotton fibre-reinforced geopolymer composites" for your consideration for publication in Composites: Part B.

In this paper, we describe the physical, mechanical and fracture behaviour of geopolymer reinforced with cotton fibres. Four different cotton fibre contents are considered as reinforcements for geopolymer composites based on fly-ash. Results show that the appropriate addition of cotton fibres can improve the mechanical properties of geopolymer composites. In particular, the flexural strength and the fracture toughness increase at an optimum fibre content of $0.5 \mathrm{wt} \%$. However, as the fibre content increases, the density of geopolymer composites decreases due to an increase in porosity.

I hope this manuscript will receive your most kind consideration and I look forward to hearing from you its outcome in due course.

Yours sincerely

Jim Low

Professor

Department of Imaging \& Applied Physics

Curtin University, Perth, WA

Australia 


\title{
Characterisation of cotton fibre-reinforced geopolymer composites
}

\author{
Alomayri T ${ }^{\mathrm{a}}$, Shaikh FUA ${ }^{\mathrm{b}}$, Low IM*a, \\ ${ }^{\mathrm{a}}$ Department of Imaging \& Applied Physics, Curtin University, GPO Box U1987, Perth, \\ WA 6845, Australia. \\ ${ }^{\mathrm{b}}$ Department of Civil Engineering, Curtin University, GPO Box U1987, Perth, WA 6845, \\ Australia. \\ *Corresponding author. Email: j.low@curtin.edu.au
}

\begin{abstract}
This paper describes the physical, mechanical and fracture behaviour of geopolymer reinforced with cotton fibres. Four different cotton fibre contents are considered as reinforcements for geopolymer composites based on fly-ash. Results show that the appropriate addition of cotton fibres can improve the mechanical properties of geopolymer composites. In particular, the flexural strength and the fracture toughness increase at an optimum fibre content of $0.5 \mathrm{wt} \%$. However, as the fibre content increases, the density of geopolymer composites decreases due to an increase in porosity.
\end{abstract}

Keywords: A. Polymer-matrix composites, B. Microstructures, B. Mechanical properties, B. Fracture toughness. 


\section{Introduction}

Geopolymers are aluminosilicate inorganic polymers which are formed from polymerisation of aluminosilicates with alkaline solutions. Geopolymers have several desirable attributes which include good mechanical properties and durability [1]. In addition, they are environmentally friendly, being derived from natural materials, and because they can be prepared at room temperature they do not emit high levels of carbon dioxide that is associated with the preparation of Portland cement $[2,3]$.

Cements have been reinforced with natural fibres for many years, particularly in developing countries that have used local materials such as bamboo, sisal, jute and coir with some success $[4,5,6]$. These natural materials are not only cheap, but their low density and favourable mechanical properties make them attractive alternatives to the synthetic fibre composites used in more industrialised countries $[7,8]$. Such naturally-occurring materials have environmental advantages since they are both renewable and non-toxic $[9,10]$.

It is well established that the choice of fibres used to reinforce concrete can affect its mechanical properties, as do decisions about how to disperse them in the matrix. The type of fibres, its form, surface properties and matrix properties, all need to be considered [11]. For instance, Rahmann et al. [12] found that bamboo fibres can improve the flexural strength of concrete, and Lin et al. [13] also observed a similar improvement in wood-fibre reinforced concrete. Similarly, the use of hemp fibres has been found to improve the fracture toughness of natural fibre-reinforced concrete (NFRC) [14]. Hitherto, no report exists on the use of cotton fibres as reinforcement for geopolymers. 
This paper presents the microstructures, physical and mechanical, properties of cotton fibre reinforced geopolymer composites. Cotton fibre-reinforced geopolymer composites with different fibre contents $(0.3,0.5,0.7$ and $1 \mathrm{wt} \%)$ were fabricated and their mechanical properties such as flexural strength, flexural modulus and fracture toughness were evaluated. Synchrotron radiation diffraction (SRD) and scanning electron microscopy (SEM) were used to characterise the phase composition, microstructure, fibre dispersion and failure mechanisms of cotton fibre reinforced geopolymer composites.

\section{Experimental investigation}

\subsection{Materials}

Low calcium fly-ash (ASTM class F), collected from the Collie power station in Western Australia, was used as the source material to prepare the geopolymer composites. The chemical composition and the microstructure of fly ash are shown in Table 1 and in Figure 7(f). Alkali resistant cotton fibres with an average length of $10 \mathrm{~mm}$, average diameter of 0.2 $\mathrm{mm}$ and density of $1.54 \mathrm{~g} / \mathrm{cm}^{3}$ were used to reinforce the geopolymer matrix. The alkaline activator for geopolymerisation was a combination of sodium hydroxide solution and sodium silicate grade D solution. Sodium hydroxide flakes with $98 \%$ purity were used to prepare the solution. The chemical composition of sodium silicate used was $\mathrm{Na}_{2} \mathrm{O} 14.7 \%$, $\mathrm{SiO}_{2} 29.4 \%$ and water $55.9 \%$ by mass.

\subsection{Preparation of geopolymer composites}


To prepare the geopolymer composites, the alkaline solution to fly ash ratio of 0.35 was used and the ratio of sodium silicate solution to sodium hydroxide solution was fixed at 2.5. Four samples of geopolymer composites reinforced with $0.3,0.5,0.7$ and $1 \mathrm{wt} \%$ cotton fibre were prepared. Additional water was added to improve the workability and dispersion of cotton fibres in the composite.

\begin{abstract}
An 8 molar concentration of sodium hydroxide solution was prepared, and combined with the sodium silicate solution one day before mixing. The fibres were added slowly to the dry fly ash in a Hobart mixer at low speed until the mix become homogeneous, at which time the alkaline solution was added. This was mixed for ten minutes on low speed and another ten minutes on high speed. The walls of the mixing container were scraped down to ensure consistency of mix. This procedure was followed for all four test specimens. Each mix was cast in 25 rectangular silicon moulds of $80 \mathrm{~mm} \times 20 \mathrm{~mm} \times 10 \mathrm{~mm}$ and placed on a vibration table for five minutes. The specimens were covered with a plastic film and cured at 105 for three hours, then rested for 24 hours before de-moulding. They were then dried under ambient conditions for 28 days.
\end{abstract}

\title{
2.3. Characterisation
}

The values of density and porosity were determined to ascertain the quality of geopolymer composite samples. The thickness, width, length and weight were measured in order to determine the density. The calculation of bulk density $\left(D_{\mathrm{b}}\right)$ was carried out by using the following equation: 


$$
D_{b}=\frac{M}{V}
$$

where $D_{\mathrm{b}}=$ bulk density, $\mathrm{M}=$ mass of the test specimen, and $\mathrm{V}=$ volume of the test specimen.

The value of apparent porosity $\left(D_{\mathrm{a}}\right)$ was determined using the Archimedes principle in accordance with the ASTM Standard (C-20) [15] and tap water was used as the immersion water. The apparent porosity $\left(D_{\mathrm{a}}\right)$ was calculated using the following equation:

$$
D_{a}=\left(\frac{m_{1}}{m_{2}-m_{3}}\right) D
$$

where $m_{1}, m_{2}$ and $m_{3}$ are the mass of the sample weighted in the balance, the mass of the sample hanging on the balance arm in the air and the mass of the sample hanging on the balance arm immersed in water respectively, and $D$ is the density of water at room temperature.

The phase compositions of fly-ash, cotton fibres, geopolymer and composite samples were characterized using synchrotron radiation diffraction (SRD). The collection of SRD data was conducted using the Powder Diffraction beamline at the Australian Synchrotron in Melbourne. The diffraction pattern of each sample was collected using an incident angle of $30^{\circ}$ and wavelength of $0.11267 \mathrm{~nm}$ or photon energy of $11.0 \mathrm{keV}$.

The microstructures and the fracture surfaces of fly ash were examined using a Zeiss EVO40 (Carl-Zeiss, Germany) scanning electron microscope (SEM). Fracture surfaces of 
geopolymer samples with dimensions of $10 \mathrm{~mm} \times 7 \mathrm{~mm} \times 5 \mathrm{~mm}$ were placed in a vacuum desiccator for two days to allow complete out-gassing before being mounted on an aluminium stub and coated with a thin layer of platinum prior to examination.

\subsection{Mechanical properties}

Three-point bend tests were conducted to determine the flexural strength, flexural modulus and fracture toughness of geopolymer composites. Five specimens, measuring $80 \mathrm{~mm} \times 20$ $\mathrm{mm} \times 10 \mathrm{~mm}$, were used in each test using a LLOYD Material Testing Machine.. The support span was $40 \mathrm{~mm}$ with a loading rate of $1.0 \mathrm{~mm} / \mathrm{min}$. The flexural strength was calculated using the following equation

$$
\sigma_{F}=\frac{3}{2} \frac{p_{m} S}{W D^{2}}
$$

where $P_{m}$ is the maximum load at crack extension, $S$ is the span of the sample, $D$ is the specimen thickness and $W$ is the specimen width. The flexural modulus was computed using the initial slope of the load-displacement curve, P/ X, using the following formula

$$
E_{F}=\frac{S^{3}}{4 W D^{3}}\left(\frac{\Delta P}{\Delta X}\right)
$$


A crack with a length to width $(a / W)$ ratio of 0.4 was introduced into the specimen using a $0.4 \mathrm{~mm}$ diamond blade to evaluate fracture toughness. The fracture toughness $\left(K_{I C}\right)$ was calculated as follows [16]:

$$
K_{I C}=\frac{p_{m} S}{W D^{2 / 3}} f\left(\frac{a}{W}\right)
$$

where $P_{m}$ is the maximum load at crack extension, $S$ is the span of the sample, $D$ is the specimen thickness, $W$ is the specimen width, $a$ is the crack length and $f(a / W)$ is the polynomial geometrical correction factor given by [19]:

$$
f\left(\frac{a}{W}\right)=\frac{3(a / W)^{1 / 2}\left[1.99-(a / W)(1-a / W) \times\left(2.15-3.93 a / W+2.7 a^{2} / W^{2}\right)\right]}{2(1+2 a / W)(1-a / W)^{2 / 3}}
$$

\section{Results and discussion}

\subsection{Synchrotron radiation diffraction}

The synchrotron radiation diffraction (SRD) patterns of commercial fly ash, cotton fibres and of prepared geopolymer reinforced with $0.3,0.5,0.7$ and $1.0 \mathrm{wt} \%$ of cotton fibres are shown in Figure 1. The diffraction pattern of cotton fibres shows typical characteristic peaks, indicating the presence of cellulose. Fly ash displays peaks caused by the presence of quartz and mullite as well as other crystalline phases. In addition, a broad peak, can be discerned in the region around $2 \theta \quad 30^{\circ}$, arising from the amorphous phase present. This amorphous phase is crucial for geopolymerisation reactions [17] which lead to the formation of a geopolymer [17, 18]. 
Comparing the SRD spectra of the original fly ash with those of the hardened geopolymeric composites, Figure lindicates that the crystalline phases (quartz, mullite, etc.) originally existed in the fly ash have apparently not been altered by the activation reactions; hence they do not participate in the geopolymerisation reaction. The diffraction patterns of geopolymer composites reinforced with $0,0.3,0.5,0.7$ and $1 \mathrm{wt} \%$ cotton fibres all showed the sharp peaks of the crystalline phases from fly ash, thus confirming that these phases are neither reactive nor involved in geopolymerisation, but are simply present as inactive fillers in the geopolymer network.

\subsection{Density and porosity of geopolymer composites}

The density and porosity values of the geopolymer composites after 28 days of curing at ambient temperature are presented in Figure 2 and Figure 3, respectively. Figure 2 shows that density decreases as the weight percent of cotton fibre increases. The geopolymer composite reinforced with $1.0 \mathrm{wt} \%$ of cotton fibre has the lowest density of $1.8 \mathrm{~g} / \mathrm{cm}^{3}$ whereas the control sample displays the highest value of $\sim 2.0 \mathrm{~g} / \mathrm{cm}^{3}$. These results are in agreement with those obtained by other investigators $[19,20]$. For instance, the study on bagasse fibre-reinforced cement composite reported that the density values decreased with increase of fibre content [19]. Similarly, in another study by Abdullah et al. on coconut fibre reinforced cement, they reported that density values of cement composites decreased with increasing fibre content [20].

The value of porosity increases with increases in the weight percent of cotton fibres as shown in Figure 3. The lowest value of porosity (20\%) is found in the control sample that 
contained no cotton fibres whereas the composite containing the highest amount of cotton fibre has the highest porosity of $30 \%$.

The effect of the initial water content on density and porosity has perhaps the most important implications in this study. In order to reduce the viscosity of the geopolymer composites with 0.7 and $1.0 \mathrm{wt} \%$ of cotton fibres, a high water/fly ash ratio was required, and this caused an increase of porosity in the resulting composites. The addition of extra water results in larger amounts of "free" water that is trapped in inter-granular space or large pores after geopolymerisation and evaporates during curing and extended ageing, leaves large quantities of inter-granular pores in the microstructure [21, 22].

The increase in porosity with increasing cotton fibre content may also be explained by the fact of water absorbed by the fibres. It is possible that fibres tend to clump together during mixing, entrapping water-filled spaces that subsequently turn into voids. Thus increased fibre content may enhance the potential for fibre clumping which is undesirable for achieving a uniform microstructure [23].

\subsection{Mechanical properties}

\subsubsection{Flexural strength and modulus}

The effects of fibre content on the flexural strength and flexural modulus of cotton fibrereinforced geopolymer composites are shown in Figure 4 and Figure 5, respectively. In

Figure 4, experimental results indicate that the flexural strength of composites increases initially with increasing cotton fibre content of up to $0.5 \mathrm{wt} \%$, and then decreases 
thereafter. The enhancement in flexural strength may be ascribed to the good dispersion of cotton fibres throughout the matrix which helps to increase the interaction or adhesion at the matrix/cotton fibre interface. Hence, this permits the optimum operation of stresstransfer from the matrix to the cotton fibres, thus resulting in the improvement of strength properties. However, the flexural strength of composites decreases when fibre content increases to more than $0.5 \mathrm{wt} \%$ (see Figure $7(\mathrm{~d}-\mathrm{e})$ ) where a high content of cotton fibres inhibits the non-homogeneity within the matrix such that agglomerations are formed which degrade the interfacial adhesion between the fibre and the matrix . In addition, these agglomerations may act as stress concentrators to cause reductions in flexural strength [24].

It was observed that increasing the content of cotton fibre caused discernible increase in matrix viscosity, which in turn allowed residual air bubbles to be introduced either through mixing or by being trapped in the geopolymer during pouring into the mould. These conditions may be implicated in sample failure at relatively low stress. A lower loading of cotton fibres offers less potential for microvoid formation and more uniform dispersion; both contribute to strength improvement.

The flexural strength of the neat geopolymer paste increased from 10.4 to $11.7 \mathrm{MPa}$ after the addition of $0.5 \mathrm{wt} \%$ cotton fibres. However, adding more cotton fibres $(0.7$ and $1.0 \mathrm{wt}$ $\%)$ led to a reduction in strength.

The flexural moduli of geopolymer composites are shown in Figure 5, and indicate similar trends to flexural strength values. The addition of $0.5 \mathrm{wt} \%$ cotton fibres in the geopolymer 
matrix increases the flexural modulus over plain geopolymer, but this trend reverses, reducing to 0.95 and $0.80 \mathrm{GPa}$, with the addition of 0.7 and $1.0 \mathrm{wt} \%$ cotton fibres. Two reasons may account for this observation: (1) increased viscosity, voids, and poor dispersion due to high cotton fibre content; and (2) presence of high proportion of other constituents (e.g. quartz and mullite) which act as inactive fillers and thus leads to insufficient geopolymer binders. The presence of quartz in a source material is particularly undesirable when designing geopolymers because it can cause microcracking, which reduces the strength of the material. This problem becomes more significant as the particle size of the quartz increases [18]. The presence of small amount of cotton fibres in the geopolymer matrix serves to counteract this, thereby increasing the flexural strength and flexural modulus of the geopolymer composites over plain geopolymer. The optimum content of cotton fibres in geopolymer composites is $0.5 \mathrm{wt} \%$.

\subsubsection{Fracture toughness}

The effect of cotton fibre content on the facture toughness of geopolymer composites is presented in Figure 6. Cotton fibres play a significant role in enhancing the facture toughness of the matrices through several energy-absorbing functions such as fibre rupture, fibre/matrix interface debonding, fibre pull-out and fibre-bridging which slow crack propagation and therefore increase fracture energy [25-29]. The fracture toughness of geopolymer reinforced with $0.5 \mathrm{wt} \%$ cotton fibres increases by $1.12 \mathrm{MPa} \cdot \mathrm{m}^{1 / 2}$ over neat geopolymer. This significant enhancement in facture toughness is due to fibre pull-out, fibre fracture and fibre-bridging, as clearly shown in the SEM images of Figure 7(b-e). 
Some short fibres, such as poly vinyl alcohol (PVA) and basalt, have previously been employed to improve the mechanical performance of geopolymers because they provide some control of cracking and increase the fracture toughness of a brittle matrix by their bridging action during both micro and macro-cracking. It has been reported that short PVA fibres with an optimum volume fraction of $1.0 \%$ ameliorated the brittle properties of ashbased geopolymer [30]. Similarly, Dias and Thaumaturgo [31] investigated fracture toughness of geopolymeric concretes reinforced with basalt fibres and found that geopolymeric concretes with $0.5-1.0 \mathrm{wt} \%$ basalt fibres showed higher fracture toughness than Portland cement concretes. In another study, Li et al. [32] reported that the addition of basalt fibres with an optimum volume fraction of $0.3 \%$ significantly improved deformation and energy absorption capacities of geopolymeric concrete.

However, the fracture toughness decreased with increasing fibre content due to the poor dispersion of cotton fibres in the slurry. The dispersion of cotton fibre in the geopolymer matrix has a considerable influence on the properties of the fresh mix, in particular on workability. The addition of 0.7 and $1.0 \mathrm{wt} \%$ cotton fibres resulted in a reduction in the consistency of the matrix. This had to be compensated for by an increase in the water content of the mix. Increasing water content to overcome such a problem may lead to other adverse effects, such as an increase in porosity and microcracking. These limitations usually lead to the reduction in bonding at the fibre-matrix interface, which results in lower stress transferred from the matrix to the fibres. 


\section{Conclusions}

This study indicates that cotton fibres can be used as reinforcement in the development of geopolymer composites. Increasing the content of cotton fibres (up to $0.5 \mathrm{wt} \%$ ) increases the flexural strength, flexural modulus and fracture toughness of the composites. However, further increase in cotton fibre content beyond $0.5 \mathrm{wt} \%$ caused a reduction in the mechanical properties due to poor workability which led to formation of voids and fibre agglomerations. The density of geopolymer composites decreases with an increase in fibre content. SEM results show an increase in energy dissipation events for composites with lower fibre content when compared to their higher fibre content counterparts. Composites containing lower fibre contents show better fibre matrix interfacial bonding than those with higher fibre contents.

\section{Acknowledgements}

The authors would like to thank Ms E. Miller from Applied Physics at Curtin University for assistance with SEM. The authors would like to acknowledge Dr. W. Rickard and Mr. L. Vickers for assisting in mechanical tests. The collection of diffraction data was funded by the Australian Synchrotron (PD 5341).

\section{References}

1. Duxson P, Fernández-Jiménez A, Provis JL, Lukey GC, Palomo A, Deventer JSJ. Geopolymer technology: the current state of the art. J Mater Sci 2007; 42(9):2917-33. 
2. Davidovits J. Geopolymers: Inorganic polymeric new materials. J Therm Anal 1991; 37(8):1633-1656.

3. Pernica D, Reis P, Ferreira J, Louda P. Effect of test conditions on the bending strength of a geopolymer-reinforced composite, J Mater Sci 2010; 45(3):744-49.

4. Baluch H, Ziraba YN, Azad AK. Fracture characteristics of sisal fibre reinforced concrete, Int J Cem Compos Lightweight Concr 1987; 9(3):157-68.

5. Pakotiprapha B, Pama RP, Lee, SL. Behaviour of a bamboo fibre-cement paste composite, J Ferro Cem 1983; (13):235-248.

6. Ramaswamy HS, Ahuja BM, Krishnamoorthy S. Behaviour of concrete reinforced with jute, coir and bamboo fibres, Int J Cem Compos Lightweight Concr 1983; 5(1):3-13.

7. Alamri H, Low IM, Alothman Z. Mechanical, thermal and microstructural characteristics of cellulose fibre reinforced epoxy/organoclay nanocomposites, Compos Part B: Eng 2012; 43(7):2762-71.

8. Wambua P, Ivens J, Verpoest I. Natural fibres: can they replace glass in fibre reinforced plastics? Compos Sci Technol 2003; 63:1259-1264.

9. Sapuan SM, Bachtiar D, Hamdan MM.. The effect of alkaline treatment on tensile properties of sugar palm fibre reinforced epoxy composites. Mater Des 2008; 29(7):1285-90.

10. Alamri H, Low IM. Characterization of epoxy hybrid composites filled with cellulose fibres and nano-SiC, J Appl Polym Sci 2012; 126:E221-E231. 
11. Aziz MA, Paramasivam P, Lee SL. Prospects for natural fibre reinforced concretes in construction, Int J Cem Compos Lightweight Concr 1981; 3(2):123-32.

12. Rahman MM, Rashid MH, Hossain MA, Hasan MT. Performance evaluation of bamboo reinforced concrete beam, Int J Eng Technol 2011; 11(4):142-146.

13. Lin X, Silsbee MR, Roy DM, Kessler K, Blankenhorn PR. Approaches to improve the properties of wood fibre reinforced cementitious composites, Cem Concr Res 1994; 24(8):1558-66.

14. Li Z, Wang L, Wang X. Compressive and flexural properties of hemp fibre reinforced concrete, Fibres Polym 2004; 5(3):187-97.

15. Standard test methods for apparent porosity, water absorption, apparent specific gravity, and bulk density of burned refractory brick and shapes by boiling water 2000: Pennsylvania, ASTM C-20.

16. Low IM, McGrath M, Lawrence D, Schmidt P, Lane J, Latella BA, Sim KS. Mechanical and fracture properties of cellulose-fibre-reinforced epoxy laminates, Compos Part A: Appl Sci Manuf 2007; 38(3):963-74.

17. Rattanasa U, Chindaprasirt P. Influence of $\mathrm{NaOH}$ solution on the synthesis of fly ash geopolymer, Minerals Eng 2009; 22(12):1073-78.

18. Rickard WDA, Williams R, Temuujin J, van Riessen A. Assessing the suitability of three Australian fly ashes as an aluminosilicate source for geopolymers in high temperature applications, Mater Sci Eng 2011; 528(9):3390-97. 
19. Aggarwal LK, Bagasse-reinforced cement composites, Cem Concr Compos1995; 17(2):107-12.

20. Abdullah A, Jamaludin SB, Noor MM, Hussin K. Composite cement reinforced coconut fibre: physical and mechanical properties and fracture behavior, Aust J Basic Appl Sci 2011; 5(7):1228-1240.

21. Criado M, Fernández Jiménez A, Sobrados I, Palomo A, Sanz J. Effect of relative humidity on the reaction products of alkali activated fly ash, J Eur Ceram Soc 2012; 32(11):2799-807.

22. Kouamo HT, Mbey JA, Elimbi A, Kenne Diffo BB, Njopwouo D. Synthesis of volcanic ash-based geopolymer mortars by fusion method: effects of adding metakaolin to fused volcanic ash, Ceram Int 2012; 12: 8842-8862.

23. Neithalath N, Weiss J, Olek J. Acoustic performance and damping behavior of cellulose-cement composites, Cem Concr Compos 2004; 26(4):359-70.

24. Talimi M, Rizvi G. Properties enhancement of PLA-natural fibre composites using an ethylene copolymer, World J Eng 2008; 20(26):1461-1462.

25. Reis JML. Fracture and flexural characterization of natural fiber-reinforced polymer concrete, Constr Build Mater 2006; 20(9): 73-78.

26. Silva FA, Tolêdo Filho RD, Melo Filho JA, Fairbairn EMR. Physical and mechanical properties of durable sisal fibre-cement composites, Constr Build Mater 2010; 24(5):777-85. 
27. Silva FA, Mobasher B, Tolêdo Filho RD. Cracking mechanisms in durable sisal fibre reinforced cement composites, Cem Concr Compos 2009; 31(10):721-30.

28. Tolêdo Filho RD, Romildo D, Khosrow G, England GL, Scrivener K. Development of vegetable fibre-mortar composites of improved durability, Cem Concr Compos 2003; 25(2):185-96.

29. Tolêdo Filho RD, Romildo D, Scrivener K, England GL, Ghavami K. Durability of alkali-sensitive sisal and coconut fibres in cement mortar composites, Cem Concr Compos 2000; 22(2):127-43.

30. Zhang Y, Sun W, Li Z. Impact behavior and microstructural characteristics of PVA fiber reinforced fly ash-geopolymer boards prepared by extrusion technique, J Mater Sci2006; 41(10):2787-94.

31. Dias DP, Thaumaturgo C. Fracture toughness of geopolymeric concretes reinforced with basalt fibres, Cem Concr Compos 2005; 27(1):49-54.

32. Li W, Xu J. Mechanical properties of basalt fibre reinforced geopolymeric concrete under impact loading, Mater Sci Eng 2009; 505(1-2):178-86. 


\section{Table}

Table1: Chemical composition of fly ash.

\begin{tabular}{|l|l|l|l|l|l|l|l|l|}
\hline $\mathrm{SiO}_{2}$ & $\mathrm{Al}_{2} \mathrm{O}_{3}$ & $\mathrm{Fe}_{2} \mathrm{O}_{3}$ & $\mathrm{CaO}$ & $\mathrm{MgO}$ & $\mathrm{SO}_{3}$ & $\mathrm{Na}_{2} \mathrm{O}$ & $\mathrm{K}_{2} \mathrm{O}$ & LOI \\
\hline $50 \%$ & $28.25 \%$ & $13.5 \%$ & $1.78 \%$ & $0.89 \%$ & $0.38 \%$ & $0.32 \%$ & $0.46 \%$ & $1.64 \%$ \\
\hline
\end{tabular}

\section{Figure Captions}

1. Synchrotron radiation diffraction patterns of (a) cotton fibres (CF), (b) fly-ash, and geopolymer composite with (c) $0.3 \mathrm{wt} \% \mathrm{CF}$, (d) $0.5 \mathrm{wt} \% \mathrm{CF}$, (e) $0.7 \mathrm{wt} \% \mathrm{CF}$, and (f) $1.0 \mathrm{wt} \%$ CF. [Legend: $1=$ Mullite, $2=$ Quartz, $3=$ Maghemite, $4=$ Hematite, $5=$ Cellulose]

2. Density of geopolymer composites as a function of fibre content.

3. Porosity of geopolymer composites as a function of fibre content.

4. Flexural strength of geopolymer composites as a function of fibre content

5. Flexural modulus of geopolymer composites as a function of fibre content.

6. Fracture toughness of geopolymer composites as a function of fibre content.

7. SEM images of (f) fly ash and the fracture surface for geopolymer composites reinforced with varying content of cotton fibres (a) 0 , (b) 0.3 , (c) 0.5 , (d) 0.7 and (e) 1 wt $\%$. 


\section{List of table and figure captions}

Table1: Chemical composition of fly ash.

Figure1. Synchrotron radiation diffraction patterns of (a) cotton fibres (CF), (b) fly-ash, andgeopolymer composite with (c) $0.3 \mathrm{wt} \% \mathrm{CF}$, (d) $0.5 \mathrm{wt} \% \mathrm{CF}$, (e) $0.7 \mathrm{wt} \% \mathrm{CF}$, and (f) $1.0 \mathrm{wt} \% \mathrm{CF}$.

[Legend: 1 = Mullite, 2 = Quartz, $3=$ Maghemite, $4=$ Hematite, $5=$ Cellulose .

Figure2. Density of geopolymer composites as a function of fibre content.

Figure3. Porosity of geopolymer composites as a function of fibre content.

Figure4. Flexural strength of geopolymer composites as a function of fibre content

Figure5. Flexural modulus of geopolymer composites as a function of fibre content.

Figure6. Fracture toughness of geopolymer composites as a function of fibre content.

Figure7. SEM images of (f) fly ash and the fracture surface for geopolymer composites reinforced with varying content of cotton fibres (a) 0 , (b) 0.3 , (c) 0.5 , (d) 0.7 and (e) 1.0 wt $\%$. 
Click here to download high resolution image

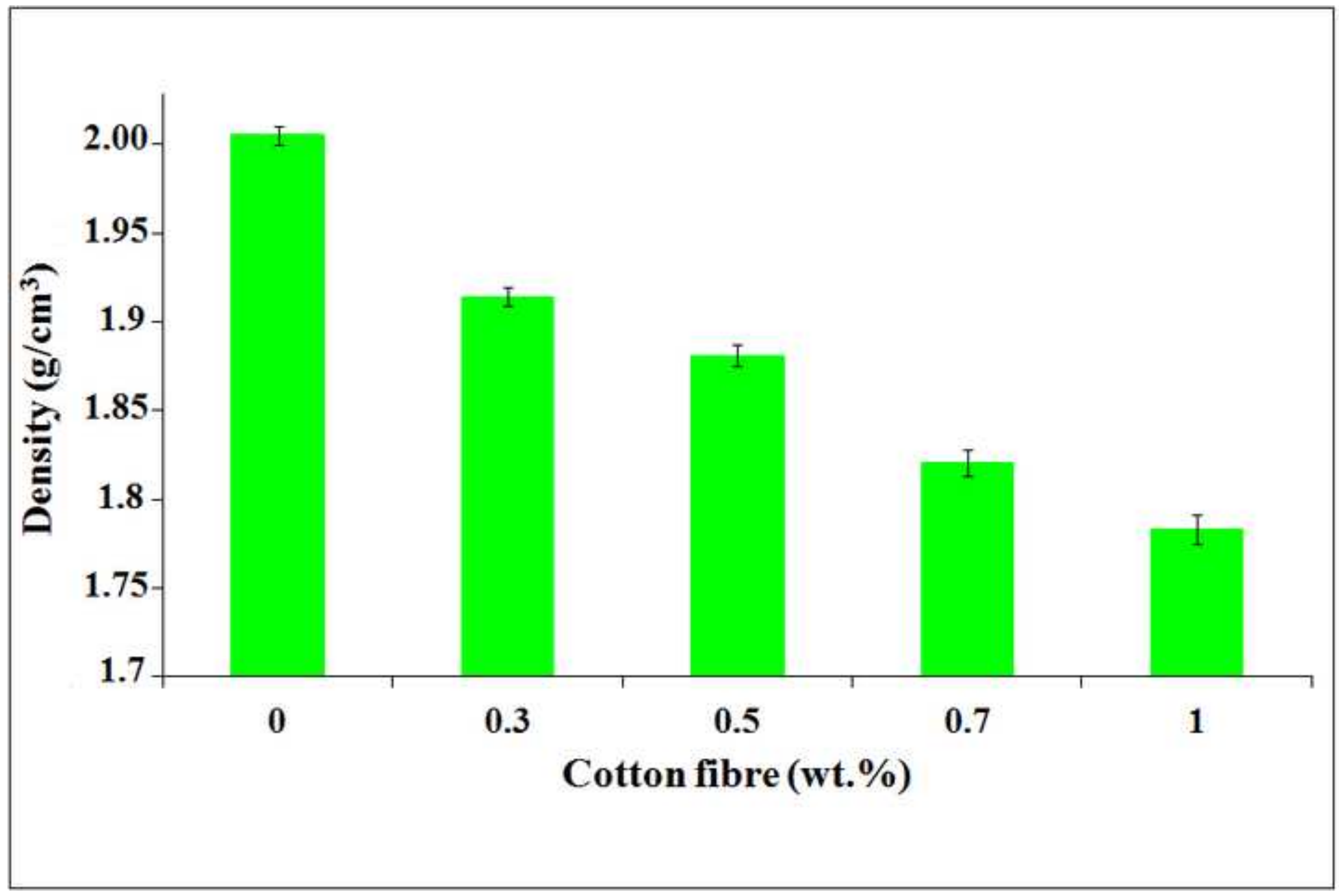


Click here to download high resolution image

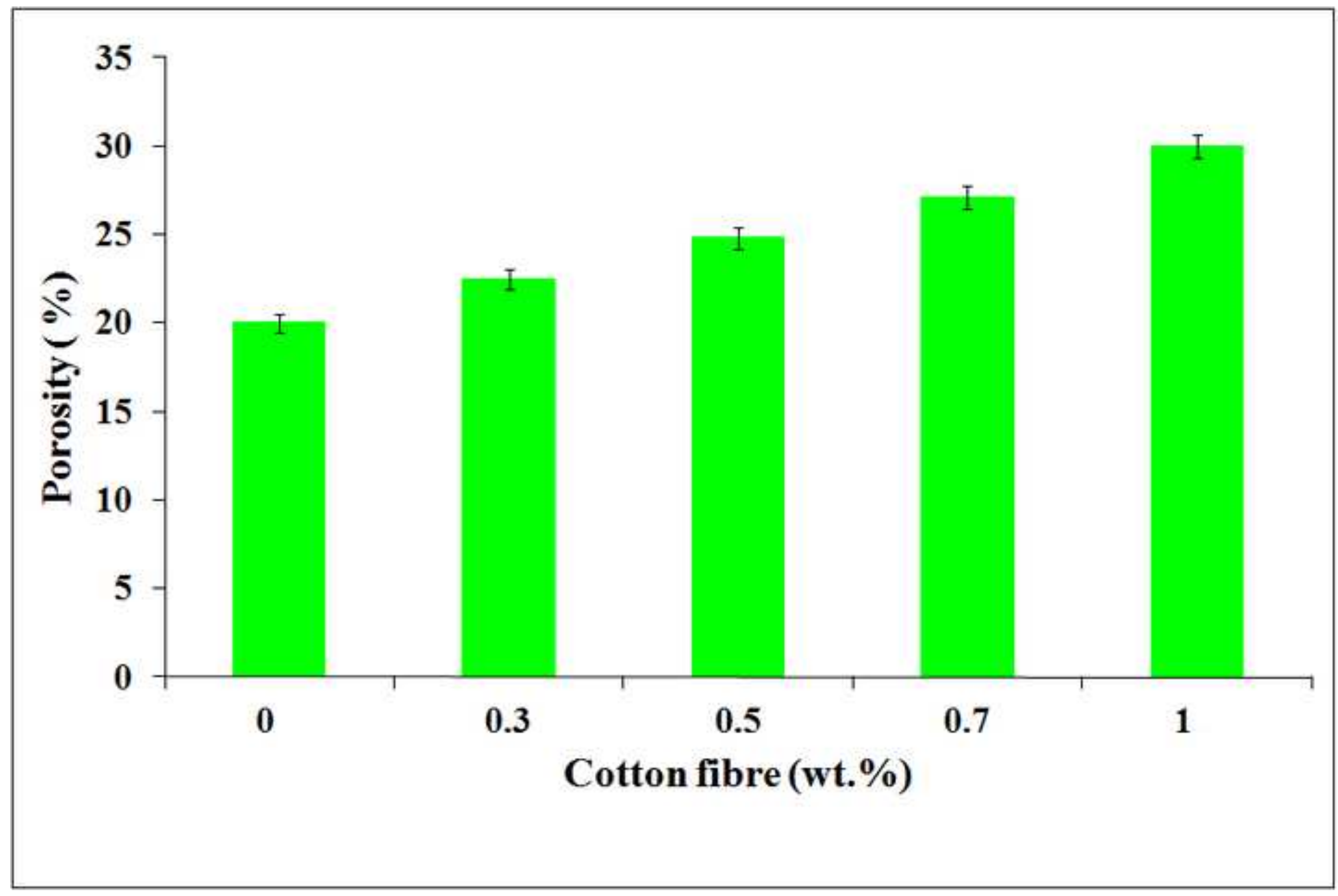




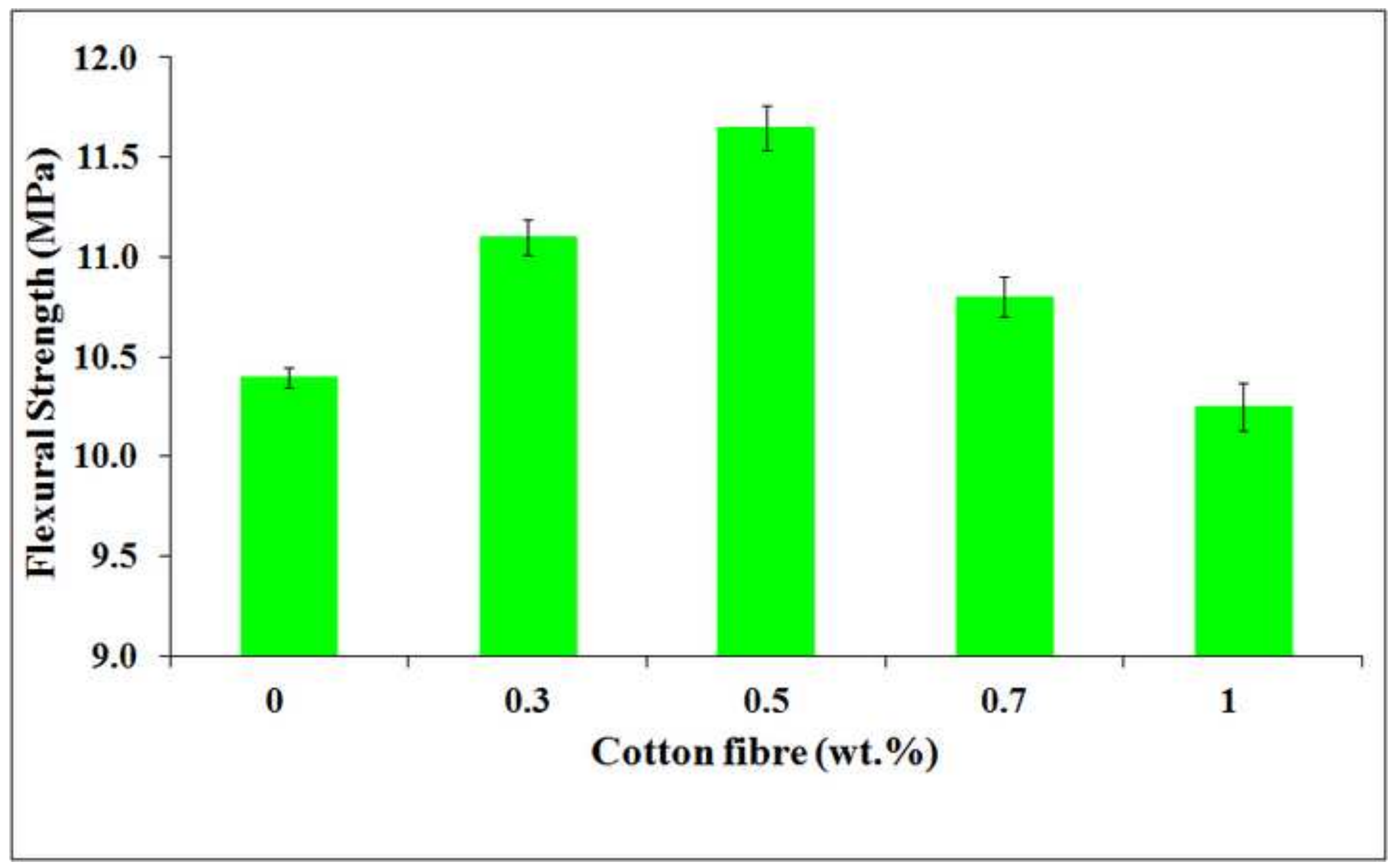




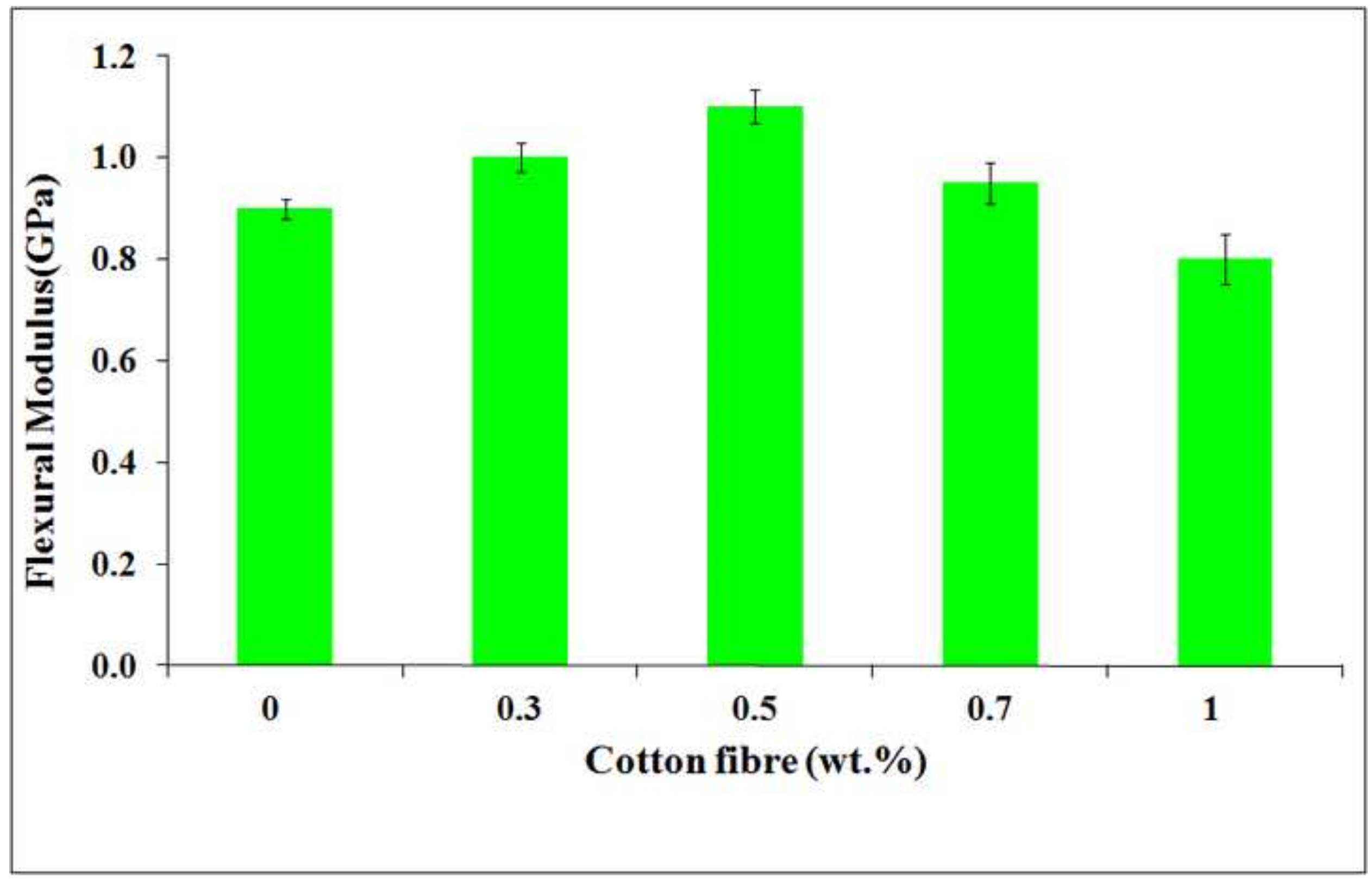




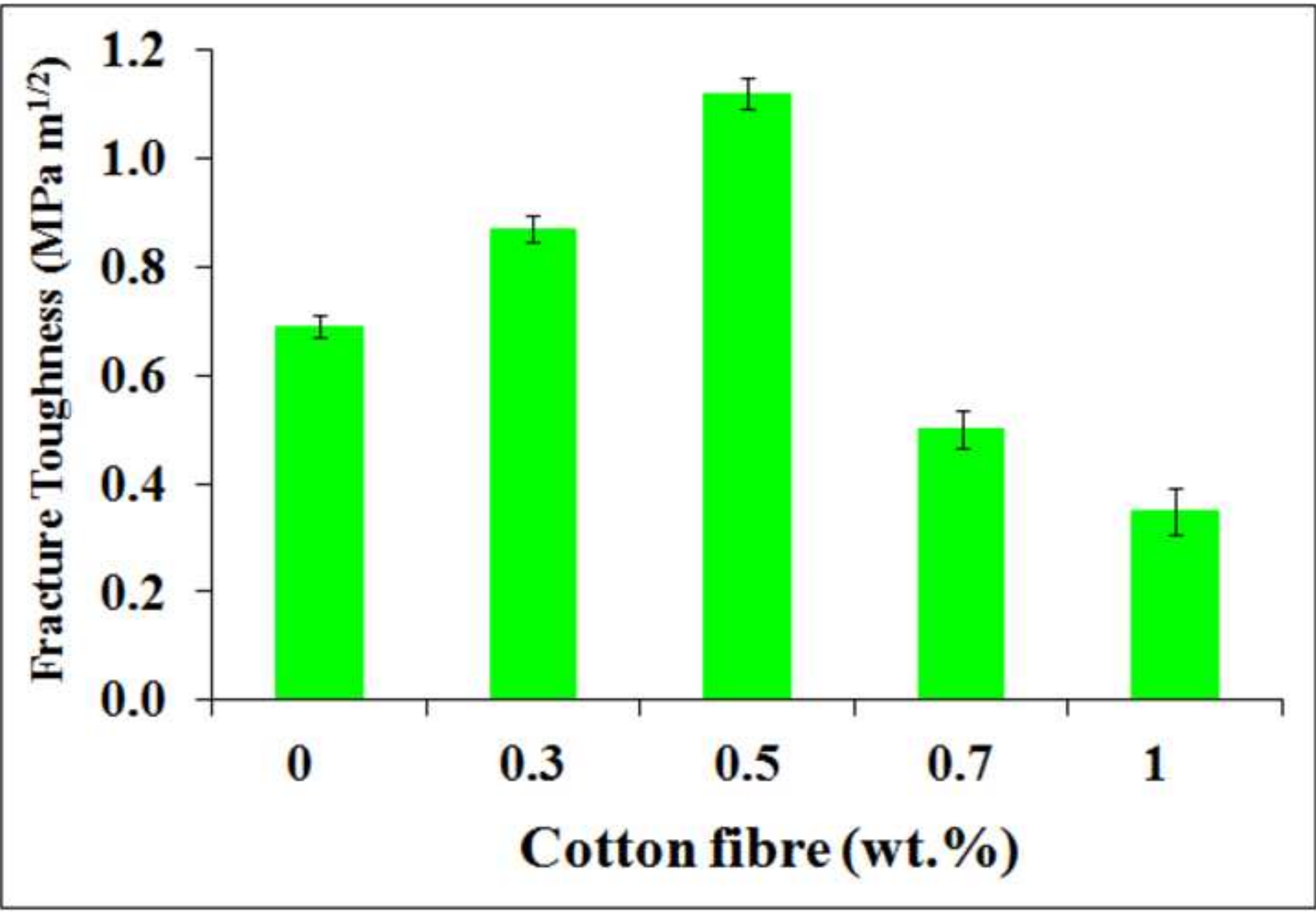




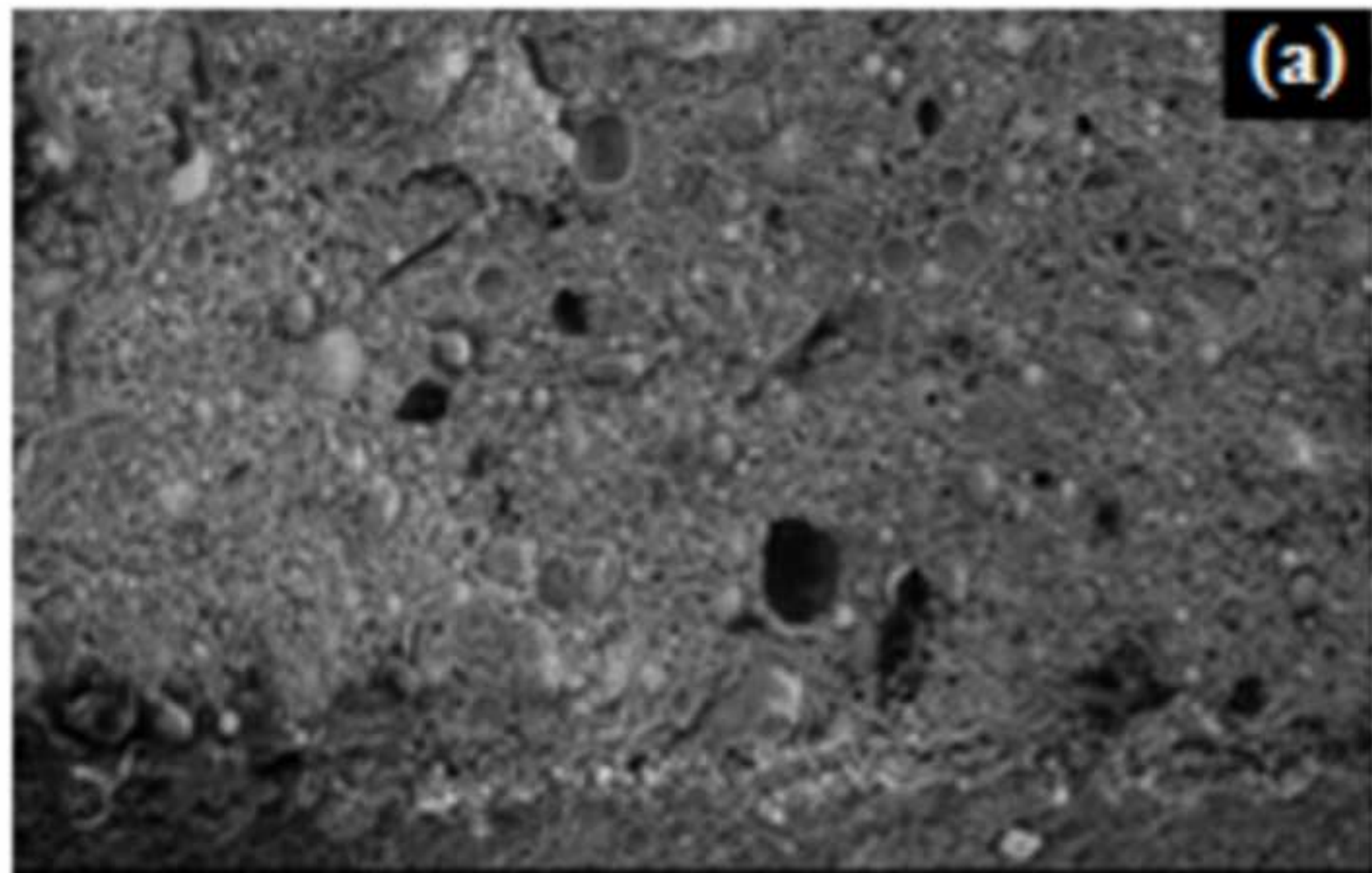

100,19

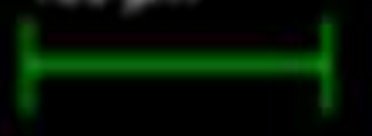

Git a 15 W W Sat tan : 48

Sorarezes Wort2sm sonat 18 st 
Click here to download high resolution image

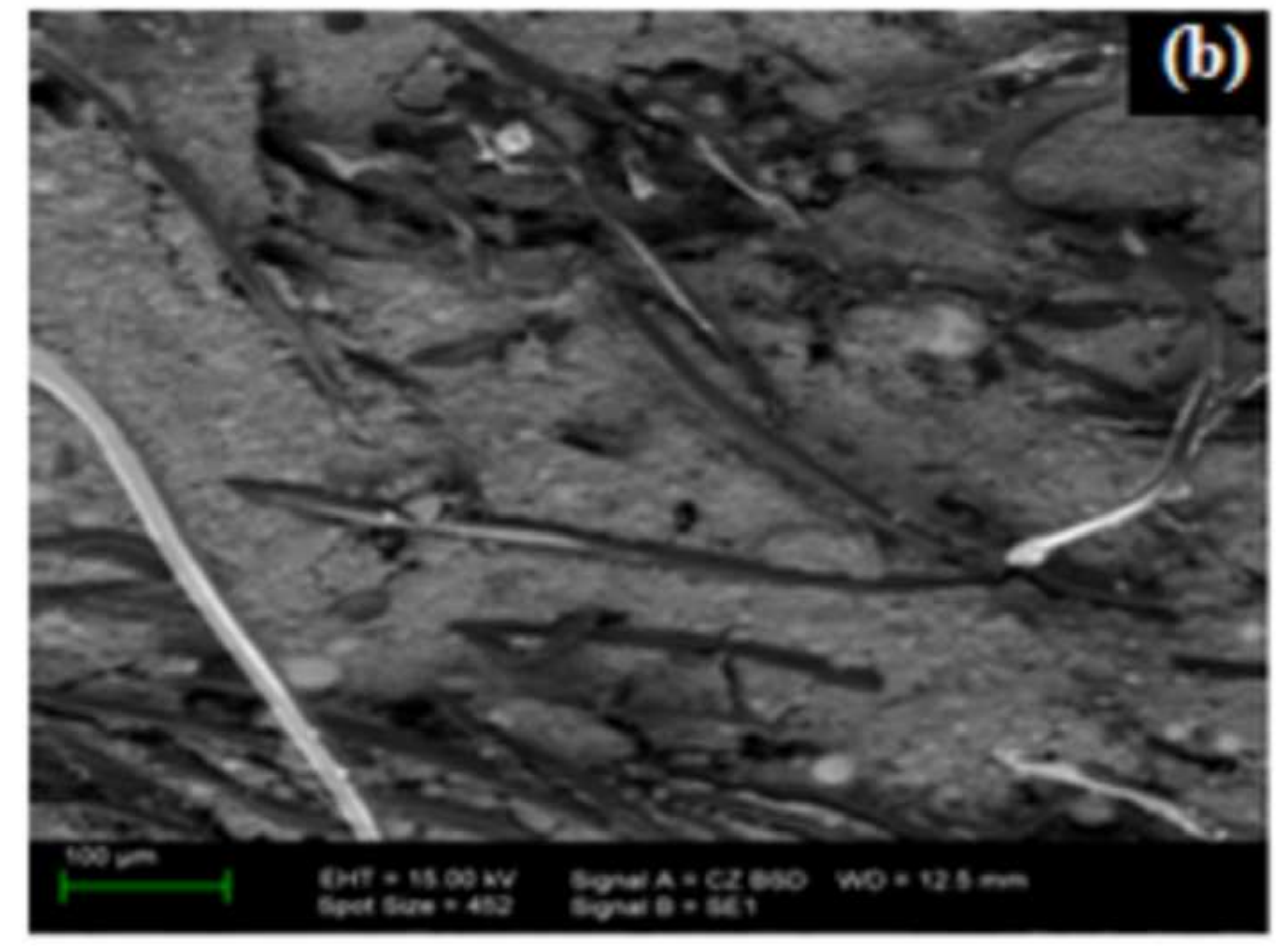
aces astas

to dow
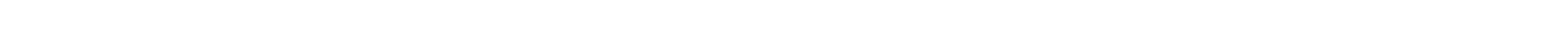
Click here to download high resolution image

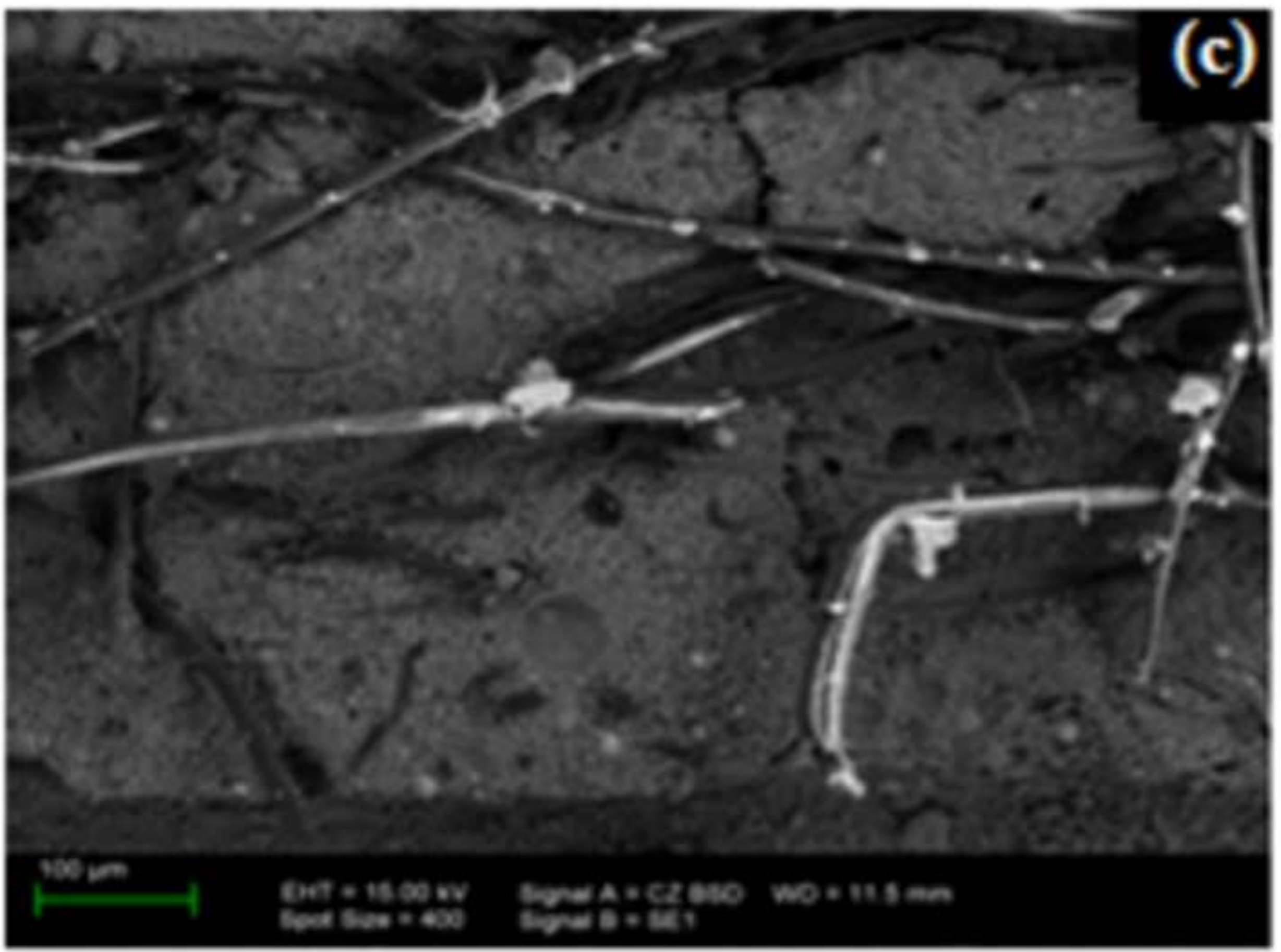


Click here to download high resolution image

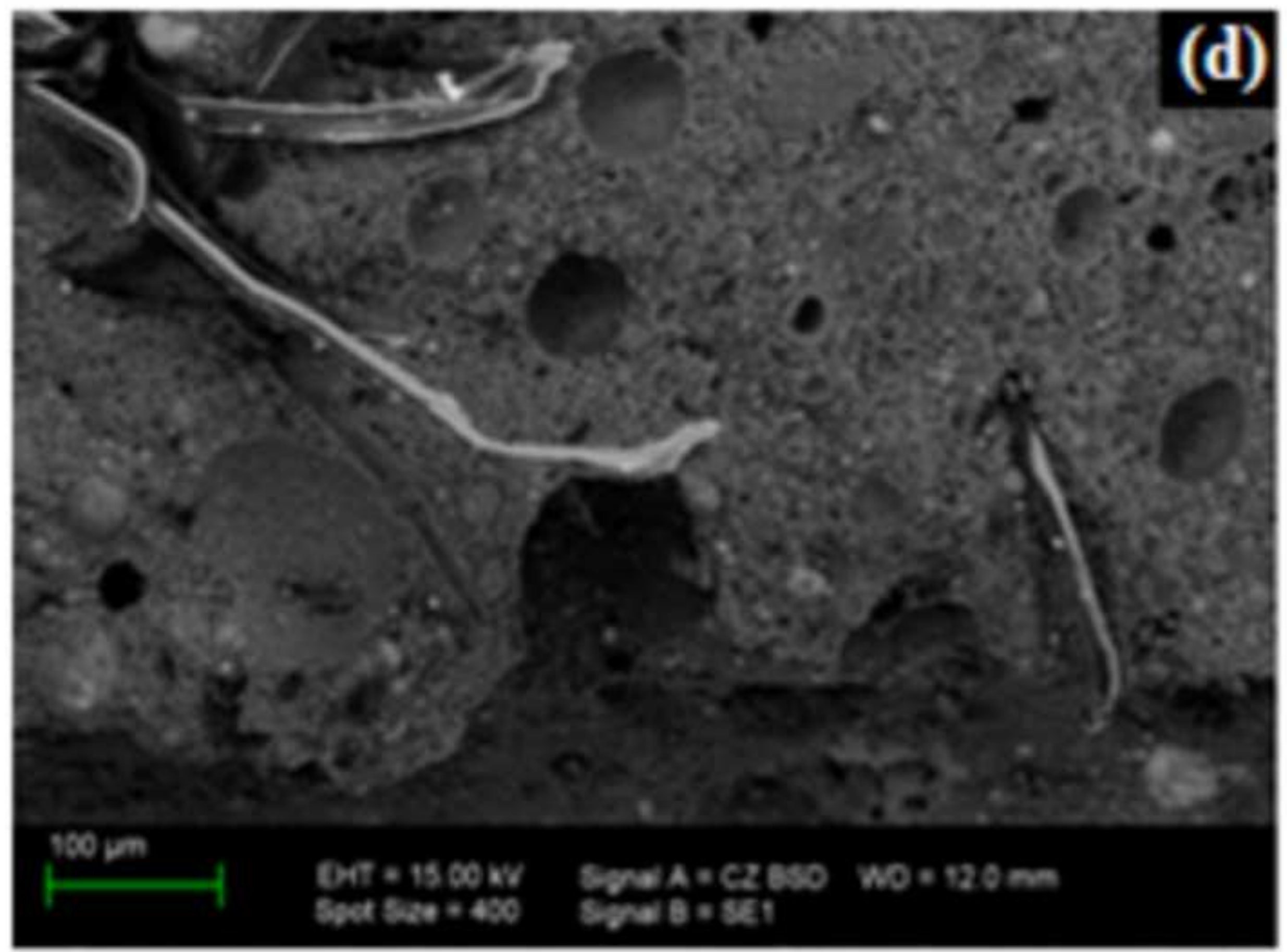


Click here to download high resolution image

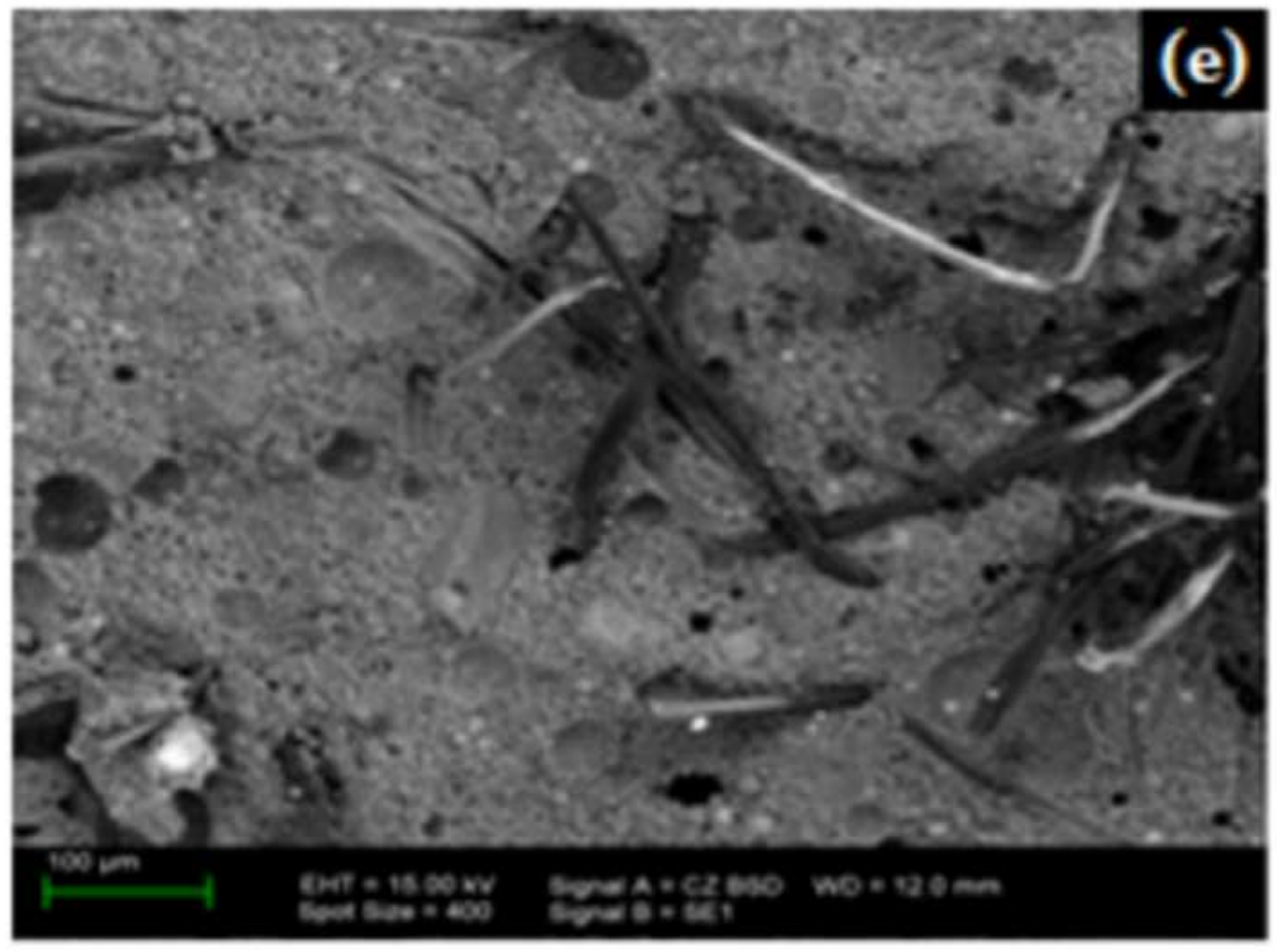

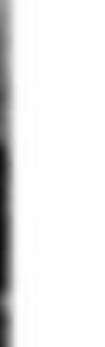
列

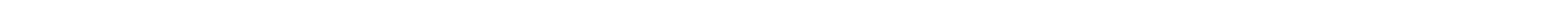


